\title{
Erratum to: Evaluation of traditionally circumscribed species in the lichen-forming genus Usnea, section Usnea (Parmeliaceae, Ascomycota) using a six-locus dataset
}

\author{
Kristiina Mark $^{1}$ - Lauri Saag ${ }^{2}$ - Steven D. Leavitt ${ }^{3} \cdot$ Susan Will-Wolf ${ }^{4}$. \\ Matthew P. Nelsen $^{5} \cdot$ Tiiu Torra $^{6} \cdot$ Andres Saag $^{1} \cdot$ Tiina Randlane $^{1}$ • \\ H. Thorsten Lumbsch ${ }^{3}$
}

Published online: 5 December 2016

(C) Gesellschaft für Biologische Systematik 2016

\section{Erratum to: Org Divers Evol (2016) 16:497-524 \\ DOI 10.1007/s13127-016-0273-7}

The MycoBank code of the newly described species Usnea parafloridana was missing. The MycoBank code for the species Usnea parafloridana should read: MB818694.

Usnea parafloridana $\mathrm{K}$. Mark, Will-Wolf \& Randlane sp. nov.; MycoBank No. MB818694.

Type: USA, Wisconsin, Vilas Co., Trout Lake Conifer Swamp State Natural Area; $46.0135^{\circ} \mathrm{N},-89.6586^{\circ} \mathrm{W}$; 27.08.2011, Susan Will-Wolf WW14807: isolates WW_018 (holotype, TU; Fig. 4a, c, e), WW_023 (isotype 1, WIS), WW_013 (isotype 2, F).

The online version of the original article can be found at http://dx.doi. org/10.1007/s13127-016-0273-7.

Kristiina Mark

kristiina.mark@ut.ee

1 Institute of Botany and Ecology, University of Tartu, Tartu, Estonia

2 Department of Evolutionary Biology, Estonian Biocentre, Tartu, Estonia

3 Science and Education, The Field Museum, Chicago, IL, USA

4 Estonia Department of Botany, University of Wisconsin-Madison, Madison, WI, USA

5 Department of Geological Sciences, Stanford University, Stanford, CA, USA

6 Estonian Marine Institute, University of Tartu, Tallinn, Estonia
Morphology: thallus shrubby, up to 3-6 cm long, often with relatively few branches; branching mainly isotomic-dichotomous, divergent; lateral branches not narrowed at point of attachment; basal part distinctly jet black, with few annular cracks; papillae verrucose, numerous on main branches and lesser or absent on lateral branches; fibrils few to numerous; soralia small and punctiform when young, enlarging, becoming close to each other but usually staying delimited when mature, more numerous on terminal branches; isidiomorphs numerous, spinulose, relatively short and thick, both on young and mature soralia; cortex thick (9-15\%); medulla thin (10.5$13 \%)$, dense, not pigmented; central cord thick $(60-73 \%)$ and white; apothecia not seen (Fig. 4; colour illustrations in online version). Secondary chemistry: usnic acid in cortex; norstictic acid as a major compound, salazinic acid as an accessory substance (present in most examined specimens) in medulla. Ecology: on branches of Abies balsamea, Larix laricina, Picea mariana, or Pinus strobus in cedar swamp, conifer bog and pine plantation with trees over one-hundred years old. Distribution: currently 15 specimens are known from four localities in Wisconsin, USA. Etymology: the species is morphologically somewhat similar to Usnea subfloridana (both taxa have similar shrubby thalli, black basal parts and delimited soralia with numerous isidiomorphs), which phylogenetically appears conspecific with $U$. florida. The same root 'florida' is used in the epithet of the new taxon to underline this morphological similarity while the prefix "para-" indicates phylogenetic distinctness of the species from $U$. florida and $U$. subfloridana. 